\title{
Clinical signs and symptoms of oropharyngeal aspiration and dysphagia in children
}

\author{
K. Weir*\#, S. McMahon , L. Barry*, I.B. Masters ${ }^{+}$and A.B. Chang ${ }^{+, \S}$
}

ABSTRACT: The diagnostic value of various signs and symptoms (clinical markers) in predicting oropharyngeal aspiration (OPA) or swallowing dysfunction has not been established in children. The present retrospective study was undertaken to: 1) identify specific clinical markers associated with radiographic evidence of OPA, isolated laryngeal penetration (ILP) and postswallow residue (PSR); 2) determine the sensitivity and specificity of clinical markers associated with OPA; and 3) determine the influence of age and neurological impairment on clinical markers of OPA.

In total, 11 clinical markers of dysphagia were compared with the videofluoroscopic swallow study (VFSS) results (OPA, ILP and PSR) in 150 children on diets of thin fluid and purée consistencies. Chi-squared and logistic regression were used to analyse the association between clinical markers and VFSS-identified swallowing dysfunction.

In children with OPA, wet voice (odds ratio (OR) 8.90, 95\% confidence interval (Cl) 2.87-27.62), wet breathing (OR 3.35, 95\% $\mathrm{Cl} 1.09-10.28$ ) and cough (OR 3.30, 95\% $\mathrm{Cl} 1.17-9.27$ ) were significantly associated with thin fluid OPA. Predictive values included: wet voice (sensitivity 0.67; specificity 0.92 ); wet breathing (sensitivity 0.33 ; specificity 0.83 ); and cough (sensitivity 0.67 ;

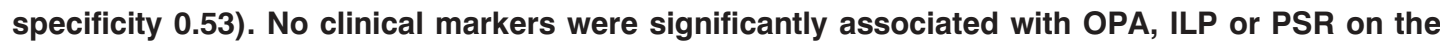
purée consistency. Cough was significantly associated with PSR on thin fluids (OR $3.59,95 \% \mathrm{CI}$ 1.22-10.55). Differences were found for age.

Wet voice, wet breathing and cough were good clinical markers for children with oropharyngeal aspiration on thin fluid but not on purée. Age and neurological status influenced the significance of these clinical markers.

KEYWORDS: Aspiration, clinical signs, dysphagia, modified barium swallow, oropharyngeal aspiration, videofluoroscopy

eeding and swallowing disorders are prevalent in children and are often complex and multifactorial in nature [1, 2]. A respiratory consequence of this is oropharyngeal aspiration (OPA), for which evaluations may include the videofluoroscopic swallow study (VFSS) or fibreoptic endoscopic evaluation of swallowing, nuclear studies such as salivagrams or nuclear scintigraphy, bronchoscopy and gastrointestinal studies [3]. Children at risk for OPA are often referred to a speech pathologist or feeding specialist for a clinical feeding evaluation, to evaluate a child's safety for oral intake, oral sensorimotor and swallowing function and feeding efficiency [4]. The clinical feeding evaluation generally includes a case history and observation of the child's feeding and swallowing function, which includes noting clinical signs of feeding or swallowing difficulty or symptoms associated with OPA. This information usually provides a working diagnosis for the nature of the dysphagia and guides direction for further investigation or intervention [4].

Clinicians utilise a variety of symptoms and signs as indicators of OPA and swallowing dysfunction, including cough, wheeze, recurrent pneumonia, gagging, choking, congestion, tachypnoea, bradycardia, apnoea, cyanosis with feeds, oxygen desaturations, noisy or wet breathing, delayed swallows and voice changes [5-9]. In addition, signs such as gurgly respiration or wet voice can also be associated with hypopharyngeal or laryngeal pooling of secretions, or pharyngeal residue of food materials $[5,10]$. Some authors suggest that airway responses to OPA are age dependent, with

\section{AFFILIATIONS}

*Depts of Speech Pathology, ${ }^{+}$Respiratory Medicine, Royal Children's Hospital

\#Dept of Paediatrics and Child Health, University of Queensland, "SpeechNet Speech Pathology Services, Brisbane, and ${ }^{\S}$ Child Health Division, Menzies School of Health Research, Charles Darwin University, Darwin, Australia.

\section{CORRESPONDENCE}

K. Weir

Speech Pathology Dept

Level 4 Coles Health

Services Building

Royal Children's Hospital

Herston Rd

Herston

QLD 4029

Australia

Fax: 61736361978

E-mail: Kelly_Weir@

health.gld.gov.au

Received:

June 152008

Accepted after revision:

October 122008

SUPPORT STATEMENT

The present study was supported by the Speech Pathology Association of Australia (Melbourne) and the Royal Children's Hospital Foundation (Brisbane, Australia)

\section{STATEMENT OF INTEREST}

None declared. 
infants demonstrating a combination of apnoea, vocal cord constriction, rapid swallowing and bradycardia (laryngeal chemoreflexes) [11], while older children and adults typically demonstrate a cough response [8, 12]. The clinical feeding evaluation and the use of clinical signs is known to have poor reliability in detecting aspiration compared with objective evaluation of swallowing during a VFSS, especially in neurologically impaired children, where the presence of silent aspiration or aspiration without an obvious cough or choking is likely [13] While cough may be absent, the presence of other clinical markers of OPA may alert the clinician to suspect that aspiration has occurred. However, symptoms and signs utilised as indicators of OPA and swallowing dysfunction have not been systematically examined. The sensitivity and specificity of specific symptoms and signs in predicting OPA and laryngeal penetration have also not been established.

Thus, further knowledge about the relationship between clinical signs and specific swallowing dysfunction would be clinically useful. In the current study of 150 children, the association of commonly reported symptoms and signs suggestive of OPA with VFSS-identified OPA and swallowing dysfunction were examined. It was hypothesised that specific radiographical signs of swallowing dysfunction were more likely to be associated with specific clinical symptoms and signs. The current study aims were to: 1) identify specific clinical symptoms and signs associated with radiographical evidence of OPA, isolated laryngeal penetration (ILP) and post-swallow residue (PSR); 2) determine the sensitivity and specificity of signs and symptoms associated with OPA; and 3) determine the influence of age and neurological impairment on these symptoms and signs of OPA.

\section{METHODS}

The medical records and VFSS results of 150 children who attended a VFSS at the Royal Children's Hospital, Brisbane (Australia) between April 11, 2001 and August 4, 2004 were reviewed retrospectively and have been previously described $[14,15]$. Briefly, children's medical files, VFSS referrals and results of clinical feeding evaluations were reviewed for clinical signs or symptoms associated with OPA and swallowing dysfunction during feeding. The 11 examined clinical signs or symptoms (henceforth referred to as clinical markers) included: cough (defined as any cough response occurring during the clinical feeding evaluation once ingestion had commenced); wheeze; stridor; throat clearing; gagging; choking; desaturations and apnoeas during feeding; wet voice (voice that is gurgly or liquid sounding) [10,16]; wet or gurgly breathing; laboured breathing during feeds; and temperature spikes $\left(>38.5^{\circ} \mathrm{C}\right)$ during a 24 -h period following oral intake. Desaturation was defined as a fall below $90 \%$ arterial oxygen saturation measured by pulse oximetry $\left(S \mathrm{p}, \mathrm{O}_{2}\right)$ for any length of time where a good trace was observed and no movement artefact was noted. Apnoea was defined as a halt in respirations and facial colour change observed visually, with an accompanying oxygen desaturation $<90 \% \mathrm{Sp}_{\mathrm{p}} \mathrm{O}_{2}$ requiring interruption of the feed at least once per feed for more than one feed, as noted by medical/nursing staff. Clinical markers were chosen from reported presentations of oropharyngeal dysphagia and aspiration from the literature [7, 8, 10, 17].
A standardised VFSS procedure and data collection has been in practice in the VFSS clinic since 1998, as previously described [14, 15]. Children's VFSS results for every food or fluid consistency trialled during the examination were recorded on a data sheet, which required comment on swallow function across oral preparatory, oral and pharyngeal phases of the swallow. For the purposes of the current study, three specific types of swallowing dysfunction were identified based on the following definitions: 1) OPA was defined as the passage of material below the level of the true vocal folds [18, 19]; 2) ILP was defined as entry of material into the laryngeal vestibule, but not passing below the true vocal folds [18, 19], and where laryngeal penetration was observed in the absence of aspiration occurring on any of the swallows for a given consistency [20]; and 3) PSR was defined as a pharyngeal residue evident in the pharynx post swallow [21]. OPA and ILP were rated as absent or present. PSR ratings (graded one for normal to four for severe impairment) [15] were recoded as absent or present where PSR denoted moderate to severe residue. Data on silent aspiration, defined as the passage of material below the level of the true vocal folds [18, 19], where no radiographically identified laryngeal response (e.g. cough) was observed within $20 \mathrm{~s}$ [22], were included for interest.

\section{Analysis}

Three sets of analyses were conducted. First, the relationship between the three types of swallowing dysfunction (OPA, ILP and PSR) and each clinical marker was analysed for the whole group data. Note that OPA included all children with aspiration, both overt and silent and no separate analysis was conducted for silent aspiration as this was considered to be a subset of OPA. Univariate analysis was conducted using Chi-squared and odds ratios (ORs) with 95\% confidence intervals (CIs), and then multivariate analysis using binary logistic regression. Sensitivity and specificity were then calculated for statistically significant markers of OPA for the whole group data. Secondly, the group was split into two age groups ( $\leqslant 1 \mathrm{yr}$ and $>1 \mathrm{yr}$ ) and, thirdly, the group was split according to neurological status (neurological versus nonneurological). Univariate analysis using Chi-squared and ORs (95\% CI) was used to determine age/neurological status differences in the presence of specific clinical markers and types of swallowing dysfunction, and which clinical markers were associated with OPA. Binary logistic regression was then used to determine the relative influence of each specific marker with OPA.

\section{RESULTS}

\section{Whole group data}

In total, 150 children were included: 89 (59.3\%) males and 61 $(40.7 \%)$ females with a median age of 16 months (mean age 37 months; range 2 weeks -247 months). Children were trialled on diets of different consistencies appropriate for their age including thin fluids for 132 children and purées for 127 children. The percentage of children with a swallowing dysfunction is shown in figure 1. OPA, silent aspiration and ILP, but not PSR, occurred significantly more frequently on fluids than on purée. The differences (95\% CI) between proportions were: OPA $0.19(0.09-0.28)$; silent aspiration 0.13 (0.05-0.22); ILP 0.15 (0.05-0.24); and PSR -0.10 (-0.21-0.002). The frequencies of clinical markers for any food/fluid 

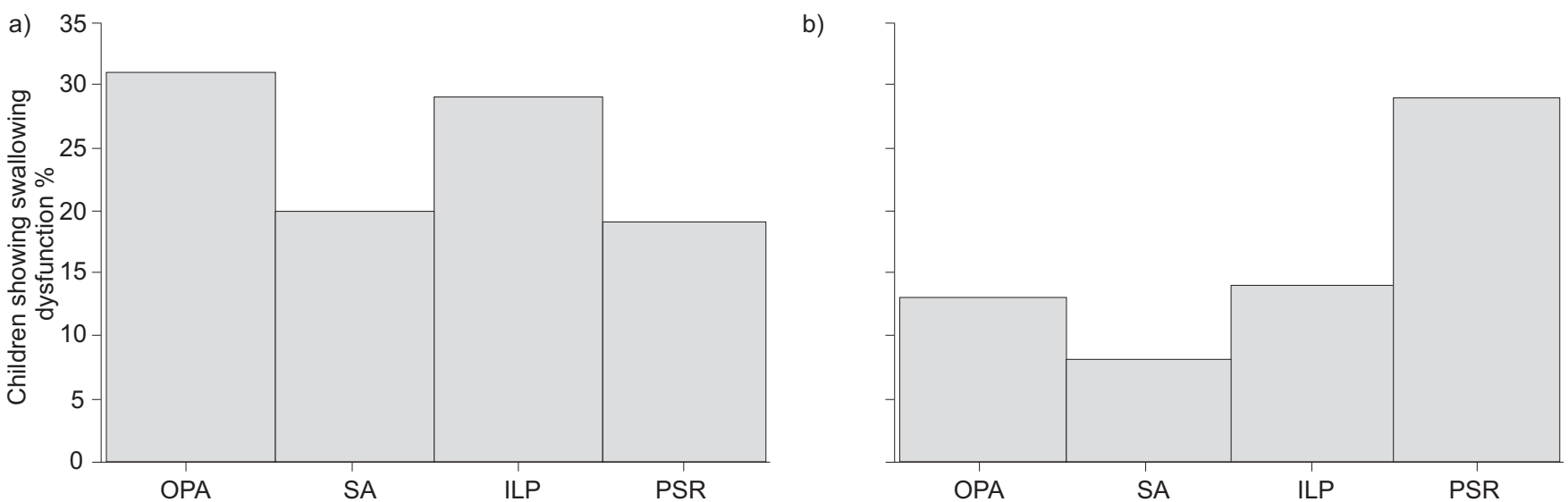

FIGURE 1. Percentage of children showing swallowing dysfunction on diets of a) thin fluid consistency ( $n=132)$ and b) purée consistency ( $n=127)$. OPA: oropharyngeal aspiration; SA: silent aspiration; ILP: isolated laryngeal penetration; PSR: post-swallow residue.

consistency trialled are presented in table 1. Of the clinical markers noted, cough was the most frequent $(46 \%)$, followed by wet/gurgly breathing (32\%), gagging (29\%), choking $(22 \%)$ and wet voice $(19 \%)$.

Univariate and multivariate regression analyses examining the association between specific clinical markers and types of swallowing dysfunction (OPA, ILP and PSR) for both fluid and purée consistencies are presented in table 2 . In the univariate analysis, cough, apnoea/desaturations, wet voice and wet breathing were significantly associated with VFSS-documented OPA children on thin fluid. Cough, wet voice and wet breathing remained significant after multivariate analysis. The sensitivity, specificity, positive predictive value, negative predictive value and positive likelihood ratio for each of the clinical markers that remained significant for thin fluid OPA following multivariate analysis are displayed in table 3. For children with OPA on purées, none of the clinical markers were significant following multivariate analysis. None of the clinical markers were significantly associated with ILP for both thin fluids and purées (table 3). Cough was significantly associated with PSR for thin fluids following univariate and multivariate analysis. While wet voice was initially significantly associated with PSR for purées, this was no longer significant following multivariate analysis (table 2).

\section{The influence of age groups on clinical markers}

Overall, $35 \%(n=53)$ of children were aged $\leqslant 1$ yr and $65 \%$ $(n=97)$ were $>1$ yr of age. Coughing, gagging, wet voice and wet breathing were frequently recorded for both age groups (table 1). The group aged $\leqslant 1 \mathrm{yr}$ were more likely to demonstrate clinical markers of stridor (OR 9.17, 95\% CI 2.46-34.24; $\mathrm{p}<0.001$ ), apnoea/desaturations (OR 15.44, 95\% CI 3.33-71.57; $\mathrm{p}<0.001$ ) and wet/gurgly breathing (OR 2.58, 95\% CI 1.16-5.73; $p=0.018)$ than the older group. However, there were no group differences in the presence of other clinical markers.

In total, $92 \%$ (49 out of 53 ) of the group aged $\leqslant 1$ yr were trialled on thin fluids and $60 \%$ (32 out of 53) had purées. Overall, $86 \%$ (83 out of 97 ) of the group aged $>1 \mathrm{yr}$ were trialled on thin fluids and $97 \%$ (95 out of 97) had purées.

\begin{tabular}{|c|c|c|c|c|c|c|c|}
\hline Clinical markers & Whole group & Age $\leqslant 1$ yr & Age $>1 \mathrm{yr}$ & $\mathrm{p}$-value & Neurological & Non-neurological & $p$-value \\
\hline Subjects $\mathrm{n}$ & 150 & 53 & 97 & & 106 & 44 & \\
\hline Cough & $69(46)$ & $20(38)$ & $49(50)$ & 0.133 & $47(44)$ & $22(50)$ & 0.527 \\
\hline Wheeze & $9(6)$ & $4(8)$ & $5(5)$ & 0.555 & $6(6)$ & $3(7)$ & 0.786 \\
\hline Throat clearing & $8(5)$ & $1(2)$ & $7(7)$ & 0.165 & $7(7)$ & $1(2)$ & 0.282 \\
\hline Gagging & $44(29)$ & $14(26)$ & $30(31)$ & 0.562 & $31(29)$ & $13(30)$ & 0.971 \\
\hline Choking & $33(22)$ & $9(17)$ & $24(25)$ & 0.273 & $24(23)$ & $9(21)$ & 0.768 \\
\hline Apnoea/desaturations & $15(10)$ & $13(25)$ & $2(4)$ & $<0.001^{*}$ & $9(9)$ & $6(14)$ & 0.339 \\
\hline Wet voice & $29(19)$ & $13(25)$ & $16(17)$ & 0.234 & $21(20)$ & $8(18)$ & 0.818 \\
\hline Wet/gurgly breathing & $32(21)$ & $17(32)$ & $15(16)$ & $0.018^{*}$ & $23(22)$ & $9(22)$ & 0.886 \\
\hline
\end{tabular}




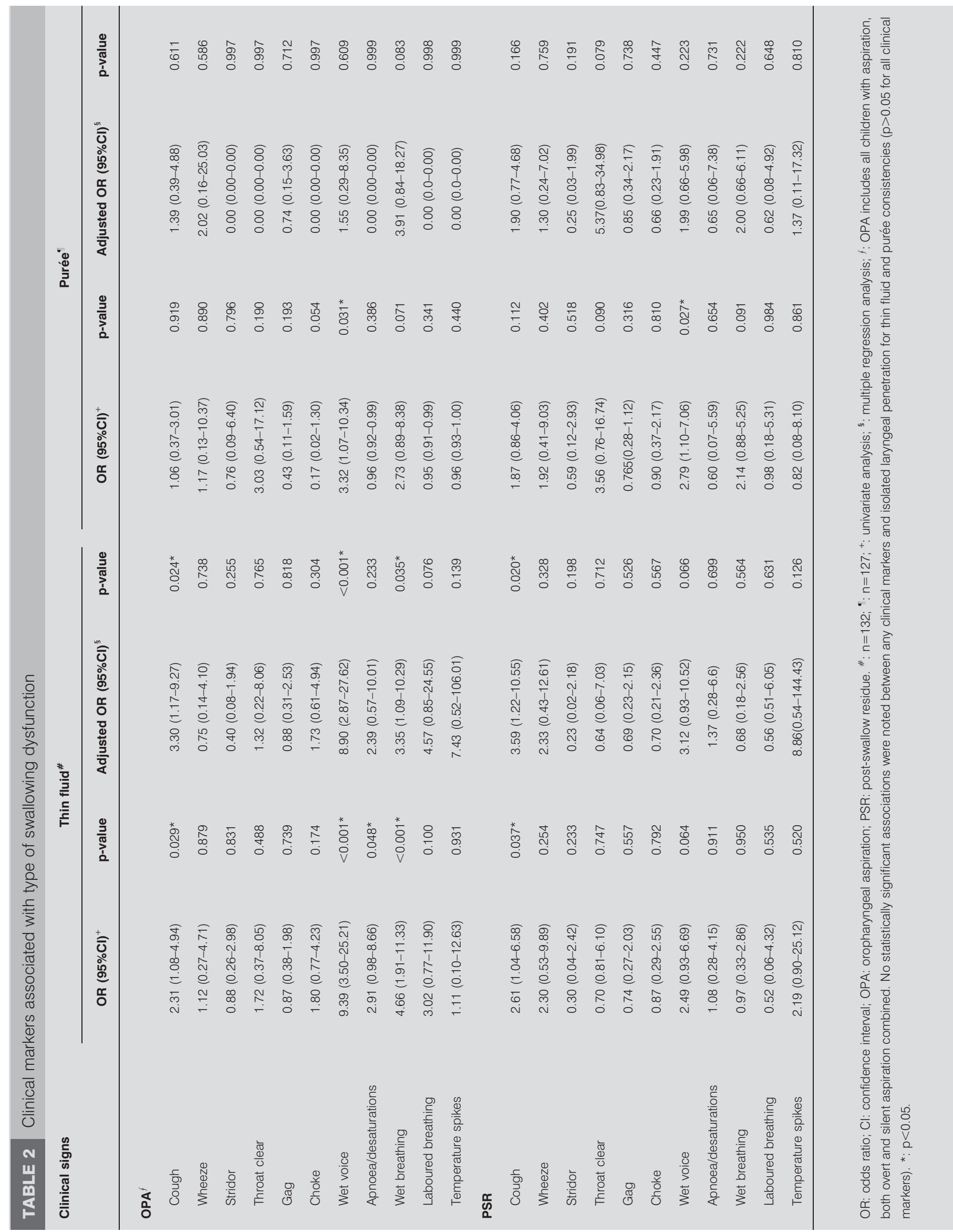


TABLE 3 Predictive values of clinical markers for thin fluid oropharyngeal aspiration

\begin{tabular}{|c|c|c|c|c|c|}
\hline Clinical marker & Sensitivity & Specificity & Positive predictive value & Negative predictive value & Positive likelihood ratio \\
\hline Cough & 0.67 & 0.53 & 0.19 & 0.90 & 1.41 \\
\hline Wet voice & 0.67 & 0.92 & 0.57 & 0.94 & 8.00 \\
\hline Wet breathing & 0.33 & 0.83 & 0.25 & 0.88 & 1.00 \\
\hline
\end{tabular}

Swallowing dysfunction on thin fluid and purée consistencies for the group comparisons (table 4) showed that OPA, silent aspiration and ILP were equally likely to occur in the two age groups but PSR was less likely to occur in the younger age group for both thin fluids (OR 0.36, 95\% CI 0.13-1.03; $\mathrm{p}=0.049$ ) and purées (OR $0.35,95 \%$ CI $0.12-0.99 ; \mathrm{p}=0.43$ ). However, there was a significant difference with the presence of neurological impairment between the age groups, with the group aged $>1$ yr 2.78 times more likely to have a neurological impairment than the younger group (95\% CI 1.34-5.74; $\mathrm{p}=0.005)$.

As OPA was the type of swallowing dysfunction of primary interest, clinical markers associated with OPA were analysed for the two age groups. Wet voice was the only clinical marker significantly associated with OPA on thin fluids in the group aged $\leqslant 1$ yr following univariate (OR 21.43, 95\% CI 3.81$120.48 ; \mathrm{p}<0.001)$ and regression analysis (OR $16.55,95 \%$ CI $2.30-119.21 ; \mathrm{p}=0.005)$. The group aged $>1 \mathrm{yr}$ demonstrated more clinical markers associated with OPA on thin fluids in the univariate analysis: wet breathing (OR 17.10, 95\% CI 3.3487.66; $\mathrm{p}<0.001$ ); laboured breathing (OR 8.29, 95\% CI $0.82-$ 84.11; $\mathrm{p}=0.037$ ); wet voice (OR 5.40, 95\% CI 1.55-18.83; $\mathrm{p}=0.005$ ); and choking (OR 3.12, 95\% CI 1.10-8.85; $\mathrm{p}=0.029$ ). However, only wet breathing remained significant following multivariate regression analysis (adjusted OR 28.54, 95\% CI 3.83-207.44; $\mathrm{p}=0.001)$. Cough, stridor, throat clearing, gagging, apnoea/desaturations and temperature spikes did not have any association with OPA on thin fluids in either age group. No clinical markers were significantly associated with OPA on

\begin{tabular}{|c|c|c|c|c|c|c|}
\hline TABLE 4 & $\begin{array}{l}\text { Age c } \\
\text { dysfur }\end{array}$ & $\begin{array}{l}\text { mparis } \\
\text { tion on }\end{array}$ & $\begin{array}{l}\text { result } \\
\text { hin fluic }\end{array}$ & $\begin{array}{l}\text { for sv } \\
\text { and } p\end{array}$ & $\begin{array}{l}\text { owing } \\
\text { e consi }\end{array}$ & encies \\
\hline \multirow{2}{*}{$\begin{array}{l}\text { Type of } \\
\text { swallow } \\
\text { dysfunction }\end{array}$} & \multicolumn{3}{|c|}{ Thin fluids } & \multicolumn{3}{|c|}{ Purée } \\
\hline & $\leqslant 1 \mathbf{y r}$ & $>1 \mathrm{yr}$ & $p$-value & $\leqslant 1 \mathrm{yr}$ & $>1 \mathrm{yr}$ & $\mathrm{p}$-value \\
\hline Subjects $\mathrm{n}$ & 49 & 83 & & 32 & 95 & \\
\hline OPA $^{\#}$ & 17 (35) & $24(29)$ & 0.488 & $4(13)$ & $12(13)$ & 0.985 \\
\hline $\begin{array}{l}\text { Silent } \\
\text { aspiration }\end{array}$ & $14(26)$ & $16(19)$ & 0.264 & $2(4)$ & $10(11)$ & 0.182 \\
\hline ILP & $13(27)$ & $25(30)$ & 0.660 & $4(13)$ & $14(20)$ & 0.754 \\
\hline PSR & $5(10)$ & $20(24)$ & $0.049^{*}$ & $5(15)$ & $32(34)$ & $0.043^{*}$ \\
\hline
\end{tabular}

Data are presented as $n(\%)$, unless otherwise stated. OPA: oropharyngeal aspiration; ILP: isolated laryngeal penetration; PSR: post-swallow residue. The total number of children aged $\leqslant 1 \mathrm{yr}$ and $>1 \mathrm{yr}$ were 53 and 97 , respectively. \#: data for OPA includes all children with OPA, both overt and silent aspiration combined. *: $p<0.05$ purées in the group aged $\leqslant 1 \mathrm{yr}$, whereas wet breathing (OR 5.21, 95\% CI 1.3-19.60; $\mathrm{p}=0.009$ ) and wet voice (OR 4.68, $95 \%$ CI 1.26-17.35; $p=0.014$ ) were significantly associated in the group aged $>1$ yr. Only wet breathing remained significant after regression analysis (adjusted OR 8.91, 95\% CI 1.38-57.45; $\mathrm{p}=0.022)$.

\section{The influence of neurological impairment on clinical markers}

In total, $71 \%$ (106 out of 150) of children had a neurological impairment (neurological group), while $29 \%$ (44 out of 150) did not (non-neurological group). There were no differences in the frequencies of reported clinical markers between these two groups (table 1), although differences were found for VFSSidentified swallowing dysfunction (table 5). Children in the neurological group were more likely to have OPA on thin fluids (OR 3.82, 95\% CI 1.46-10.00; $\mathrm{p}=0.004$ ), PSR on thin fluids (OR 4.21, 95\% CI 1.18-14.96; $\mathrm{p}=0.018$ ) and PSR on purées (OR $5.30,95 \%$ CI $1.50-18.69 ; p=0.005)$ than children in the nonneurological group.

On univariate analysis, clinical markers significantly associated with OPA on thin fluids in the neurological group were: cough (OR 2.53, 95\% CI 1.06-60.7; $\mathrm{p}=0.034)$, wet voice (OR $8.50,95 \%$ CI 2.50-28.85; $\mathrm{p}<0.001$ ), and wet breathing (OR 6.67, $95 \%$ CI 2.13-20.87; $\mathrm{p}<0.001$ ). Only wet voice (adjusted OR 10.06, 95\% CI 2.20-45.94; $\mathrm{p}=0.003$ ) and wet breathing (adjusted OR 8.88, 95\% CI 1.94-40.77; $\mathrm{p}=0.005$ ) had a continued significant association following regression analysis. Clinical markers significantly associated with OPA on thin fluids in the non-neurological group following univariate analysis were wet voice (OR 22.00, 95\% CI 2.78-174.06; p<0.001) and apnoea/ desaturations (OR 11.00, 95\% CI 1.50-80.43; $\mathrm{p}=0.007$ ), although only wet voice (adjusted OR 33.97, 95\% CI 1.33-868.73; $\mathrm{p}=0.033$ ) had a continued significant association following regression analysis. No clinical markers were significantly associated with OPA on purées or with other types of swallowing dysfunction, including ILP or PSR, for children on either thin fluids or purées (data not shown) in either the neurological or non-neurological group.

\section{DISCUSSION}

The present study of 150 children examined the occurrence of clinical markers suggestive of swallowing dysfunction for three specific types of swallowing dysfunction (OPA, ILP and PSR), as identified by the VFSS using thin fluid and purée consistencies. Coughing, wet voice and wet breathing were significantly associated with OPA on thin fluids, but not on purées. No clinical markers were associated with children with ILP or PSR on purées. Cough was associated with PSR on thin fluids. The influence on clinical markers of age groups $(\leqslant 1$ and 


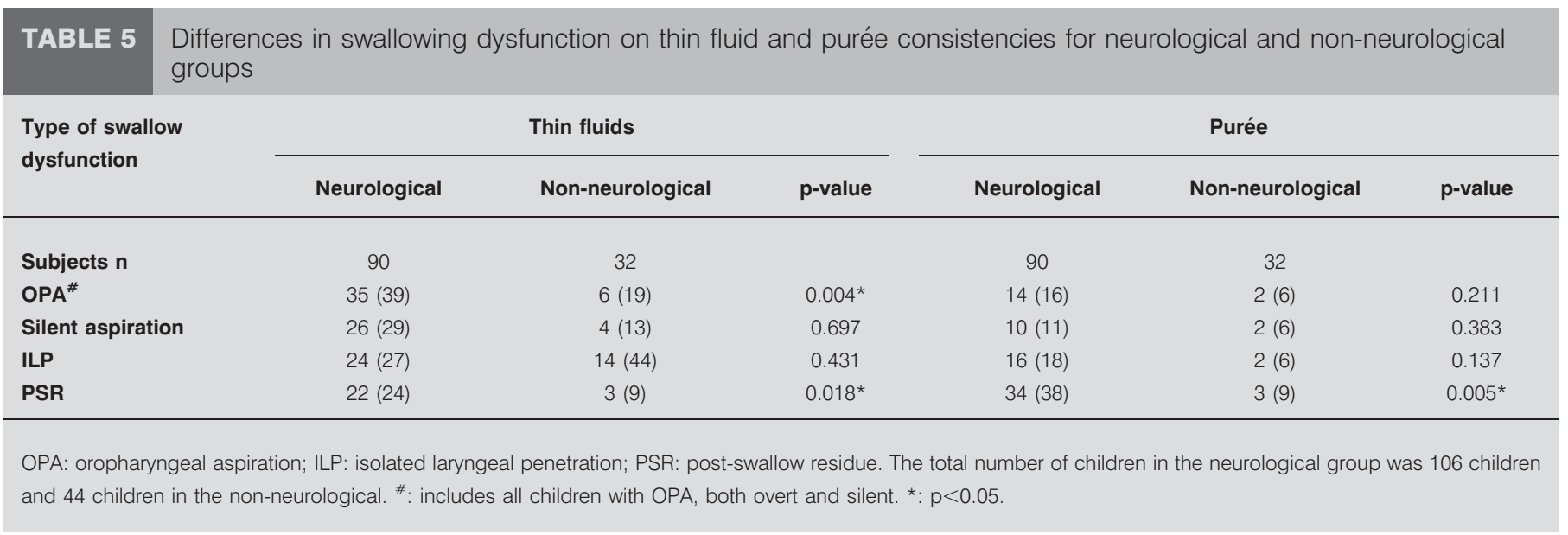

$>1$ yr of age) and the presence of neurological impairment were also examined. In infants wet voice was significantly associated with OPA on thin fluids, whereas in older children with OPA, wet breathing was significantly associated with thin fluids and purées. No clinical markers were associated with ILP or PSR on either food/fluid consistency for the two age groups. Wet voice and wet breathing were also associated with OPA on thin fluids in the neurological group of children, while wet voice was notable in the non-neurological group.

\section{Clinical markers associated with swallowing dysfunction}

Recurrent small volume aspiration is associated with chronic lung disease in both children and adults. OPA is common in respiratory practice, yet there are limited data on the sensitivities and specificities of symptoms and signs associated with OPA. The current authors found that children who demonstrated VFSS-identified OPA on thin fluids were 8.9 times more likely to have wet voice, 3.4 times more likely to have wet breathing and 3.3 times more likely to cough during feeds/meals than children who did not aspirate. The present findings have similarities to, but also differences from the findings of DEMATTEO et al. [7], whose study on 75 children did not present data on individual clinical markers of aspiration, but instead developed prediction models of aspiration and penetration that included clusters of clinical markers. It was reported that cough was the most significant predictor of fluid aspiration in children and that a combination of cough, voice changes and gag was the best prediction model for fluid aspiration with a relative risk of 1.7 [7]. While cough and wet voice (voice changes) were identified as important clinical markers in both studies, the current authors did not find gag to be significantly associated with OPA on either food/fluid consistency in the present cohort. Other clinical markers reported in the literature to be associated with OPA, such as wheeze, stridor, throat clearing, desaturations or apnoea during feeding, laboured breathing during feeding, or temperatures following oral intake $[7,8,17]$, were also not found to be significantly associated with thin fluid aspiration in the current study. While the present authors did not find any clinical markers significantly associated with OPA on purées, DEMATTEO et al. [7] reported that colour changes and abnormal respiration presented a nonsignificant relative risk of 3.0 for solid aspiration.
The current finding of wet voice having a higher likelihood ratio than cough for OPA is in contrast to adult data. While WARMS and RICHARDS [10] found that speech pathologists had good inter-observer reliability for detecting wet voice $(r=0.85)$, wet voice itself was not a reliable predictor of aspiration or laryngeal penetration in their study of 23 adult patients. WARMS and RICHARDS [10] found that wet voice was associated with material in the larynx or trachea in only $8 \%$ (7 out of 88$)$ of penetration/aspiration episodes identified on VFSS, and where wet voice was reported to be heard, it was indicative of material in the larynx or trachea (penetration and/or aspiration) in only $15 \%$ (7 out of 47 ) of episodes. In contrast to WARMS and RICHARDS [10], the current study found wet voice to be significantly associated with OPA on thin fluids for the whole group data, for the younger age group and for both neurological and non-neurological groups. In the MARI et al. [23] study of 93 neurologically impaired adults, a history of cough was reported to have higher predictive values for OPA compared with the current findings, including a sensitivity of $75 \%$, specificity of $74 \%$, positive predictive value of $71 \%$ and negative predictive value of $77 \%$ for radiographically documented aspiration. While the MARI et al. [23] study did not examine predictive values of other clinical markers, the present authors found that the highest likelihood ratio of any clinical marker for OPA was wet voice (likelihood ratio of 8.00), which suggests that cough may be a less sensitive marker of OPA in children. These differences between adults and children possibly relate to the influence of age on the structure and development of the respiratory system, such as maturation of the peripheral and central nervous systems and cortical controls of cough, laryngeal and respiratory muscles [24]. Key differences include the attenuated hypercapnic response and a paradoxical response to hypoxia in young children [25].

The current authors found that no clinical markers were associated with a finding of ILP, which suggests that it is undetectable clinically. This is in contrast to the findings of DeMATteO et al. [7], who reported that the combination of cough, gag and reflux behaviours had a statistically significant relative risk of 2.3 for fluid penetration, and a combination of colour changes and abnormal respiration had a nonsignificant relative risk of 2.6 for solid penetration. The differences between the present and the DeMATTEO et al. [7] study may 
relate to differences of definition. DeMATteo et al. [7] did not define laryngeal penetration or distinguish children with ILP (i.e. penetrators who do not also have aspiration). Thus, some of these children may have had both OPA and ILP, which may confound the real association between these clinical markers and ILP only. Laryngeal penetration with no sensorimotor response occurs frequently in normal adult populations [26] and in patients with no history or clinical suspicion for swallowing dysfunction during upper gastrointestinal studies [20]. DAGGETT et al. [26] suggested that the lack of coughing or throat clearing indicated that the normal upward and forward laryngeal movement, and the inferior-to-superior closure of the larynx during the swallow, was the normal clearance mechanism where penetration occurred in the absence of aspiration [26]. Thus, clinical markers noted in the clinical feeding evaluation would not be associated with ILP, but would be suggestive of OPA.

\section{Influence of age and neurological status}

Infants are said to demonstrate different responses to aspiration and are particularly prone to silent aspiration. It has also been suggested that cough is a less reliable indicator of aspiration in a younger age group, due to disruptions in postnatal maturation of airway clearance mechanisms or desensitisation secondary to repeated aspiration [11, 27]. In particular, apnoea has been noted to be indicative of aspiration in infants, with cessation of respiration, closure of the airway and multiple swallows until clearance of the aspirated substance has occurred [11, 28]. The current authors found that infants demonstrated stridor, apnoea/desaturations and wet breathing significantly more frequently during feeds than the older group, but none of these signs were significantly associated with OPA. Wet voice was found to be the only clinical sign associated with OPA on thin fluids in the group aged $\leqslant 1 \mathrm{yr}$, while wet breathing had a significant association with aspiration in the older group.

Reduced integrity of the cough reflex with a predisposition for silent aspiration has been consistently noted in children with neurological impairment and neurodisability [14, 29, 30]. In the current study, the neurological group was more likely to demonstrate swallowing dysfunction by the VFSS, including OPA on thin fluids and PSR on both fluids and purées, although there was no difference in the presence of cough in response to OPA (i.e. silent aspiration) between the neurological and non-neurological groups. The present finding possibly relates to the small sample size of children with OPA and silent aspiration in the non-neurological group.

Although the current study was limited by the retrospective design, the use of standard data collection forms during the medical chart/clinical feeding evaluation review and for VFSS interpretation allowed for the systematic examination of the current data in a large number of children. Wet voice is not well defined in the medical literature, but is frequently used by speech pathologists. Determination of its repeatability, validity and reliability as a sign is important but could not be examined and is another limitation of the current study.

The present authors conclude that wet voice and wet breathing are likely to be the best clinical markers of thin fluid aspiration in children. Cough was less specific in determining type of dysfunction, being associated with both oropharyngeal aspiration and post-swallow residue on thin fluids. In contrast, no clinical markers were associated with oropharyngeal aspiration on diets of purée consistency or with swallowing dysfunction associated with risk of aspiration (isolated laryngeal penetration on any consistency and post-swallow residue on purées). Further research is needed to prospectively define the clinical markers suggestive of oropharyngeal aspiration and swallowing dysfunction in different age groups and with different medical aetiologies.

\section{ACKNOWLEDGEMENTS}

The present authors appreciate the valuable assistance of N. Pandeya (Queensland Institute of Medical Research, Herston, Australia) and the staff of the Speech Pathology and Medical Imaging Departments, Royal Children's Hospital, Brisbane (Australia).

\section{REFERENCES}

1 Burklow KA, Phelps AN, Schultz JR, McConnell K, Rudolph C. Classifying complex paediatric feeding disorders. J Pediatr Gastroenterol Nutr 1998; 27: 143-147.

2 Rommel N, De Meyer AM, Feenstra L, VeeremanWauters G. The complexity of feeding problems in 700 infants and young children presenting to a tertiary care institution. J Pediatr Gastroenterol Nutr 2003; 37: 75-84.

3 Boesch RP, Daines C, Willging JP, et al. Advances in the diagnosis and management of chronic pulmonary aspiration in children. Eur Respir J 2006; 28: 847-861.

4 Arvedson JC, Rogers BT. Swallowing and feeding in the paediatric patient. In: Perlman AL, Schultz-Delrieu K, eds. Deglutition and its Disorders. San Diego, Singular Publishing Group, 1997; pp. 419-448.

5 Brodsky L. Dysphagia with respiratory/pulmonary presentation: assessment and management. Semin Speech Lang 1997; 18: 13-22.

6 Chang AB, Landau LI, Van Asperen PP, et al. Cough in children: definitions and clinical evaluation. Med J Aust 2006; 184: 398-403.

7 DeMatteo C, Matovich D, Hjartarson A. Comparison of clinical and videofluoroscopic evaluation of children with feeding and swallowing difficulties. Dev Med Child Neurol 2005; 47: 149-157.

8 Lefton-Greif MA, McGrath-Morrow SA. Deglutition and respiration: development, coordination, and practical implications. Semin Speech Lang 2007; 28: 166-179.

9 Tutor JD, Schoumacher RA. Is aspiration causing your paediatric patient's symptoms? J Respir Dis 2003; 24: 30-40.

10 Warms T, Richards J. "Wet voice" as a predictor of penetration and aspiration in oropharyngeal dysphagia. Dysphagia 2000; 15: 84-88.

11 Thach BT. Maturation and transformation of reflexes that protect the laryngeal airway from liquid aspiration from foetal to adult life. Am J Med 2001; 111: Suppl. 8A, 69S-77S.

12 Smith Hammond C. Cough and aspiration of food and liquids due to oral pharyngeal dysphagia. Lung 2008; 186: Suppl. 1, S35-S40. 
13 Seddon PC, Khan Y. Respiratory problems in children with neurological impairment. Arch Dis Child 2003; 88: 75-78.

14 Arvedson J, Rogers B, Buck G, Smart P, Msall M. Silent aspiration prominent in children with dysphagia. Int J Pediatr Otorhinolaryngol 1994; 28: 173-181.

15 Weir K, McMahon S, Barry L, Ware R, Masters IB, Chang AB. Oropharyngeal aspiration and pneumonia in children. Pediatr Pulmonol 2007; 42: 1024-1031.

16 Weir KA, McMahon SM, Long G, et al. Radiation doses to children during modified barium swallow studies. Pediatr Radiol 2007; 37: 283-290.

17 Darley FL, Aronson AE, Brown JR. Clusters of deviant speech dimensions in the dysarthrias. J Speech Hear Res 1969; 12: 462-496.

18 Ishizuka C. [Videofluorographic study of swallowing in patients with severe motor and intellectual disabilities-I. Recurrent pulmonary infections]. No To Hattatsu 2000; 32 383-389.

19 Logemann JA. Manual for the videofluorographic study of swallowing. 2nd Edn. Austin, Pro-Ed, 1993.

20 Rosenbek JC, Robbins JA, Roecker EB, Coyle JL, Wood JL. A penetration-aspiration scale. Dysphagia 1996; 11: 93-98.

21 Delzell PB, Kraus RA, Gaisie G, Lerner GE. Laryngeal penetration: a predictor of aspiration in infants? Pediatr Radiol 1999; 29: 762-765.

22 Arvedson JC, Lefton-Greif MA. Paediatric videofluoroscopic swallow studies: a professional manual with care-giver guidelines. San Antonio, Communication Skill Builders/ Psychological Corporation, 1998.

23 Mari F, Matei M, Ceravolo MG, Pisani A, Montesi A, Provinciali L. Predictive value of clinical indices in detecting aspiration in patients with neurological disorders. J Neurol Neurosurg and Psychiatry 1997; 63: 456-460.

24 Chang $\mathrm{AB}$, Widdicombe JG. Cough throughout life: children, adults and the senile. Pulm Pharmacol Ther 2007; 20: 371-382

25 Hay AD, Schroeder K, Fahey T. Acute cough in children. BMJ 2004; 328: 1062.

26 Daggett A, Logemann J, Rademaker A, Pauloski B. Laryngeal penetration during deglutition in normal subjects of various ages. Dysphagia 2006; 21: 270-274.

27 Loughlin GM, Lefton-Greif MA. Dysfunctional swallowing and respiratory disease in children. Adv Pediatr 1994; 41: 135-162.

28 Mercado-Deane M-G, Burton EM, Harlow SA, et al. Swallowing dysfunction in infants less than 1 year of age. Paediatr Radiol 2001; 31: 423-428.

29 Morton RE, Bonas R, Fourie B, Minford J. Videofluoroscopy in the assessment of feeding disorders of children with neurological problems. Dev Med Child Neurol 1993; 35: 388-395.

30 Rogers B, Arvedson J, Buck G, Smart P, Msall M. Characteristics of dysphagia in children with cerebral palsy. Dysphagia 1994; 9: 69-73. 